\title{
YC-1 induces lipid droplet formation in RAW 264.7 macrophages
}

\author{
Leo Tsuil ${ }^{1}$, Shwu-Fen Chang ${ }^{2}$, Hsiang-Po Huang ${ }^{3}$, Tsorng-Harn Fong ${ }^{4 *}$ and I-Jong Wang ${ }^{1 *}$
}

\begin{abstract}
Background: 3-(5'-Hydroxymethyl-2'-furyl)-1-benzylindazole (YC-1) is a potential anticancer drug that may activate soluble guanylyl cyclase (sGC) and increase the level of cyclic guanosine monophosphate (cGMP). The aim of this study was to explore the effects of YC-1 on lipid droplet accumulation and foam cell formation in macrophages.

Results: Human-oxidized low density lipoprotein (ox-LDL) was used to induce accumulation of lipid droplets in a murine macrophage cell line, RAW 264.7. Oil red O staining showed that treatment with $20 \mu \mathrm{M} \mathrm{YC-1} \mathrm{for} 24 \mathrm{~h}$ increased the area of intracellular lipid droplets in macrophages. The results of high content screening (HCS) with the AdipoRed ${ }^{\mathrm{TM}}$ assay further revealed that YC-1 enhanced ox-LDL-induced foam cell formation. This was evidenced by an increase in the total area of lipid droplets and the mean fluorescence intensity per cell. Inhibition of cGMPdependent protein kinase (PKG) using KT5823 significantly reduced YC-1-enhanced lipid droplet formation in oxLDL-induced macrophage foam cells.

Conclusion: YC-1 induces lipid droplet formation in macrophages, possibly through the sGC/cGMP/PKG signaling pathway. This chemical should be tested with caution in future clinical trials.
\end{abstract}

Keywords: Macrophages, Foam cells, Oxidized low density lipoproteins, YC-1, cGMP-dependent protein kinase

\section{Background}

Derived from monocytes, macrophages display tissuespecific phenotypes in different locations of the human body [1]. Macrophages regulate various aspects of normal physiology, including development, tissue homoeostasis, remodeling and repair [2]. Several reports have shown that these cells are also involved in pathological situations, especially in the initiation of the immune response, the engulfing of pathogens and the progression of atherosclerosis [3].

During atherosclerosis development, low density lipoprotein (LDL) in the plasma penetrates the artery wall and becomes oxidized to oxidized-LDL (ox-LDL), which is phagocytosed by macrophages, leading to the formation of foam cells from macrophages [4]. Accumulation of LDL in the intima of blood vessels promotes the migration of circulating monocytes to the endothelial layer

\footnotetext{
* Correspondence: thfong@tmu.edu.tw; ijong@ms8.hinet.net

${ }^{4}$ Department of Anatomy, School of Medicine, College of Medicine, Taipei Medical University, Taipei 110, Taiwan

${ }^{1}$ Department of Ophthalmology, National Taiwan University Hospital, Taipei 100, Taiwan

Full list of author information is available at the end of the article
}

and their differentiation into macrophages upon adhesion to the endothelial layer [5]. Subsequently, macrophages engulf excessive intimal lipids via several scavenger receptors [6], becoming foam cells, which have abundant membrane-bound lipid droplets in their cytoplasm [7]. Finally, the cell debris of macrophage foam cells forms the atherosclerotic plaques. Hence, it is reasonable to consider that inhibiting macrophagederived foam cell formation may be a possible target for therapeutic intervention in atherosclerosis $[5,8]$.

Recently, we have reported that $\mathrm{YC}-1$ can inhibit oleate-induced lipid accumulation in macrophages [9]. YC-1 is a chemically-synthetic benzylindazole compound, which directly activates soluble guanylyl cyclase (sGC), elevates the level of cyclic guanosine monophosphate (cGMP) in rabbit platelets, and possesses antiplatelet properties [10]. Subsequently, elevated cGMP activates cGMP-dependent protein kinase (PKG) and downstream signal transduction to regulate many cellular responses [11]. Studies have demonstrated several effects of $\mathrm{YC}-1$ on macrophages, including its ability to potentiate the release of tumor necrosis factor- $\alpha$ and nitric oxide production in alveolar macrophages $[12,13]$. 
It has also been found that $\mathrm{YC}-1$ can increase the level of cGMP and inhibit the expression of inducible nitric oxide synthase in RAW 264.7 macrophages [14]. However, the impact of YC-1 on ox-LDL-induced macrophage foam cell formation has not been addressed before. The purpose of this study was to clarify the effect of YC-1 on lipid droplet formation. We hypothesized that YC-1 may regulate lipid droplet and ox-LDLinduced foam cell formation of macrophages through the cGMP signaling pathway. To prove our hypothesis, we used high content screening (HCS), a powerful tool in biological and pharmacological research, to quantitatively detect the influence of $\mathrm{YC}-1$ on the changes in lipid droplets.

\section{Methods}

\section{Cell culture of RAW 264.7 macrophages}

A murine macrophage cell line, RAW 264.7, was purchased from the American Type Culture Collection (Manassas, VA) and cultured, as described in an earlier study [15]. In brief, RAW 264.7 macrophages were maintained in Dulbecco's Modified Eagle Medium (Invitrogen Life Technologies, Carlsbad, CA) containing $10 \%$ fetal bovine serum (Invitrogen), 100 unit $/ \mathrm{mL}$ of penicillin (Invitrogen), and $100 \mu \mathrm{g} / \mathrm{mL}$ of streptomycin (Invitrogen) at $37{ }^{\circ} \mathrm{C}$ in a humidified incubator with $5 \% \mathrm{CO}_{2}$.

\section{Reagent preparation}

YC-1 (Sigma-Aldrich) was dissolved in dimethyl sulfoxide (DMSO; Sigma-Aldrich). KT5823 (Sigma-Aldrich) was dissolved in ethyl acetate (Kanto Chemical Corporation, Tokyo, Japan).

\section{LDL oxidation}

Commercial purified human LDL (Millipore, Temecula, CA) was diluted to $0.5 \mathrm{mg} / \mathrm{mL}$ with phosphate-buffered saline (PBS; $137 \mathrm{mM} \mathrm{NaCl}, 2.7 \mathrm{mM} \mathrm{KCl}, 8 \mathrm{mM}$ $\mathrm{Na}_{2} \mathrm{HPO}_{4}$, and $1.5 \mathrm{mM} \mathrm{K \textrm {K } _ { 2 }} \mathrm{PO}_{4} ; \mathrm{pH} 7.4$ ) and oxidized with $10 \mu \mathrm{M} \mathrm{CuSO}_{4}$ (Sigma-Aldrich) at $37{ }^{\circ} \mathrm{C}$ for $24 \mathrm{~h}$ [16]. Finally, $1 \mathrm{mM}$ ethylenediaminetetraacetic acid (Sigma-Aldrich) was used to stop the oxidation. After oxidation, the ox-LDL was stored at $4{ }^{\circ} \mathrm{C}$.

\section{Oil red $O$ staining}

Oil red O powder (Sigma-Aldrich) was dissolved in 2propanol (0.5\%; Kanto Chemical Corporation). The stock was then diluted to $0.3 \%$ oil red O solution with distilled $\mathrm{H}_{2} \mathrm{O}$ and filtered through a $0.22-\mu \mathrm{m}$ filter. RAW 264.7 macrophages were seeded in a 6-well plate $\left(3 \times 10^{5}\right.$ cells/well; total $\left.2 \mathrm{~mL}\right)$ overnight. After treatment, the treated cells were washed with PBS briefly, and $1 \mathrm{~mL}$ of $0.15 \%$ glutaraldehyde (Sigma-Aldrich) was added to each well for $10 \mathrm{~min}$. The fixed cells were washed with PBS three times and stained with $0.5 \mathrm{~mL}$ $0.3 \%$ oil red $\mathrm{O}$ solution for $5 \mathrm{~min}$. Finally, the stained cells were washed with PBS three times and observed with a Nikon Eclipse E600 microscope (Nikon Instruments Inc., Tokyo, Japan) and an Evolution ${ }^{\text {tax }}$ MP digital camera (Media Cybernetics, Bethesda, MD). All experiments were repeated three times, and the representative data are shown.

\section{Cell viability assay}

3-(4,5-Dimethylthiazol-2-yl)-2,5-diphenyltetrazolium

bromide (MTT) powder (Sigma-Aldrich) was dissolved to $5 \mathrm{mg} / \mathrm{mL}$ with distilled $\mathrm{H}_{2} \mathrm{O}$. The MTT stock solution was sterilized through a $0.22-\mu \mathrm{m}$ filter and stored at $4^{\circ}$ C. RAW 264.7 macrophages were seeded in a 24-well plate $\left(10^{4}\right.$ cells/well; total $\left.0.5 \mathrm{~mL}\right)$ overnight and treated until $80 \%$ confluency. After treatment, $50 \mu \mathrm{L}$ of MTT stock solution was added to each well and incubated with $5 \% \mathrm{CO}_{2}$ at $37{ }^{\circ} \mathrm{C}$ for $2 \mathrm{~h}$. Finally, the medium was removed and $0.5 \mathrm{~mL}$ of 2-propanol was added to each well. After $5 \mathrm{~min}$ at room temperature, $200 \mu \mathrm{L}$ of solution from each well was transferred to a 96-well plate and measured at $590 \mathrm{~nm}$ by a Multiskan RC microplate reader (Thermo LabSystems, Helsinki, Finland). All experiments were repeated three times.

\section{Quantification of total lipid content}

Quantification of total lipid content was measured based on a previously-published protocol [17]. In brief, RAW 264.7 macrophages were seeded in a 24 -well plate $\left(10^{4}\right.$ cells/well; total $0.5 \mathrm{~mL}$ ) overnight and treated until $80 \%$ confluency. After treatment, the cells were stained with oil red $\mathrm{O}$, and the intracellular lipid was extracted by adding $200 \mu \mathrm{l}$ DMAO to each well. After $5 \mathrm{~min}$ at room temperature, $200 \mu \mathrm{L}$ of solution from each well was transferred to a 96-well plate. Absorbance was measured at $510 \mathrm{~nm}$ with a $\mu$ Quant microplate reader (BioTek Instruments, Winooski, VT). The quantified results were corrected after parallel experiments of cell viability assay. All experiments were repeated three times.

\section{Measurement of intracellular cGMP}

RAW 264.7 macrophages were seeded in a 24-well plate $\left(10^{4}\right.$ cells/well; total $\left.0.5 \mathrm{~mL}\right)$ overnight and treated until $80 \%$ confluency. After treatment, intracellular cGMP of macrophages was measured using cGMP Enzymeimmunoassay Biotrak System (Amersham Biosciences, Little Chalfont Buckinghamshire, UK). Absorbance was measured at $450 \mathrm{~nm}$ with a $\mu$ Quant microplate reader (BioTek Instruments, Winooski, VT). All experiments were repeated three times. 


\section{HCS with AdipoRed ${ }^{T M}$ assay}

Quantification of lipid storage compartments in macrophages and ox-LDL-induced foam cells was performed, based on a previously-published protocol [18]. RAW 264.7 macrophages were seeded in a Costar ${ }^{\circ}$ 96-well black solid plate (3000 cells/well; total $100 \mu \mathrm{L}$; Bio-Rad Laboratories, Hercules, CA). After treatment, the cells were stained with AdipoRed ${ }^{\text {tw }}$ (1:40; Lonza Walkersville, Inc., Walkersville, MD) and Hoechst 33342 (1:1000; Invitrogen) for $0.5 \mathrm{~h}$. The sample was analyzed by a Thermo Scientific Cellomics ${ }^{\circ}$ ArrayScan $^{\circ}$ VTI HCS Reader (Thermo Fisher Scientific, Pittsburgh, PA), and the Columbus ${ }^{\mathrm{Tm}}$ Image Data Storage. Analysis System software (PerkinElmer, Columbus, $\mathrm{OH}$ ) was used to recolor the images and perform the HCS image analysis. The intracellular lipid droplets were analyzed using the Spot Detector protocol of the Cellomics ${ }^{\ominus}$ HCS Reader. All HCS experiments were repeated at least three times.

\section{Statistical analysis}

All data are presented as the mean \pm standard deviation. The statistical significance of differences between groups was analyzed using one-way analysis of variance with Tukey's post hoc test by SAS version 9.4 (SAS Institute, Cary, NC). Differences with a $P$ value less than 0.05 were considered significant.

\section{Results}

YC-1 induces lipid droplet accumulation in RAW 264.7 macrophages

To analyze the effect of YC-1 on lipid droplet formation, we treated RAW 264.7 macrophages with YC-1 for different lengths of time (12, 24 and $48 \mathrm{~h}$ ) and with different doses $(10,20$ and $30 \mu \mathrm{M})$. We found that macrophages treated with 10,20 , and $30 \mu \mathrm{M} \mathrm{YC}-1$ for $24 \mathrm{~h}$ displayed a significant increase in the area of intracellular lipid droplets and total lipid content compared to the control group, as detected and quantified by oil red $\mathrm{O}$ staining (Fig. $1 \mathrm{a}$ and $\mathrm{c}$ ). We also found that macrophages treated with $20 \mu \mathrm{M} \mathrm{YC}-1$ for 12,24 or $48 \mathrm{~h}$ displayed a significant increase in lipid droplet accumulation (Fig. 2a and c). In addition, the result of the MTT cell viability assay revealed that $\mathrm{YC}-1$ did not significantly affect cell survival except with doses of $30 \mu \mathrm{M}$ (or higher) used for $24 \mathrm{~h}$ (Figs. $1 \mathrm{~b}$ and $2 \mathrm{~b}$ ). These results demonstrate that YC-1 stimulates lipid droplet formation in macrophages and suggests that $\mathrm{YC}-1$ may affect foam cell formation in macrophages.

\section{YC-1 induces foam cell formation in RAW 264.7 macrophages}

To further evaluate the effect of YC-1 on foam cell formation, commercial LDL was oxidized with copper ions and was then used to induce the formation of lipid-laden
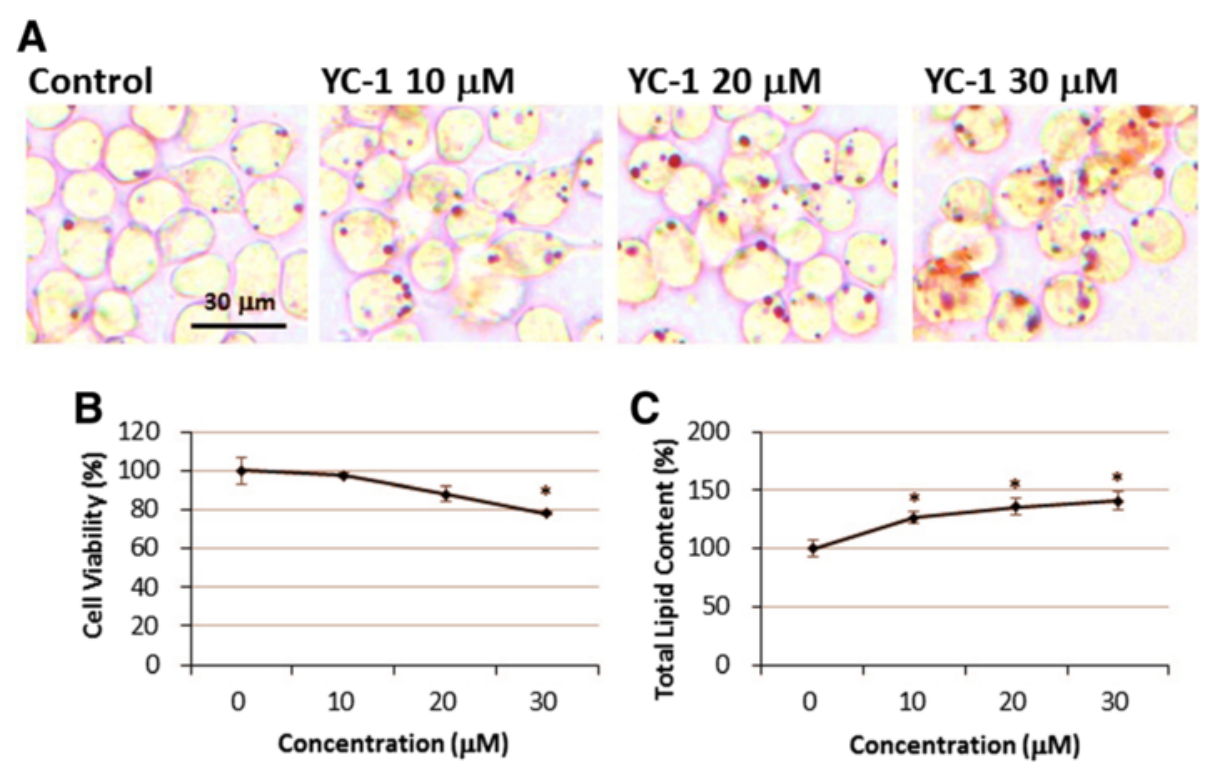

Fig. 1 The effect of different doses of YC-1 on lipid droplet formation and cell viability in RAW 264.7 macrophages. a Dosage-dependent YC-1 enhanced lipid droplet formation. RAW 264.7 macrophages were treated with different concentrations of YC-1 for $24 \mathrm{~h}$. After fixation and staining with oil red $\mathrm{O}$, the cells were observed by light microscopy. Scale bar $=30 \mu \mathrm{m}$. b $30 \mu \mathrm{M}$ YC-1 reduced the cell viability of macrophages. RAW 264.7 macrophages were treated with different concentrations of YC-1 for $24 \mathrm{~h}$ and the cell viability was measured by the MTT assay $(n=6)$. $\mathbf{c}$ Quantification of total lipid content of macrophages $(n=6) .{ }^{*}$ indicates $P<0.05$ compared to the control group 

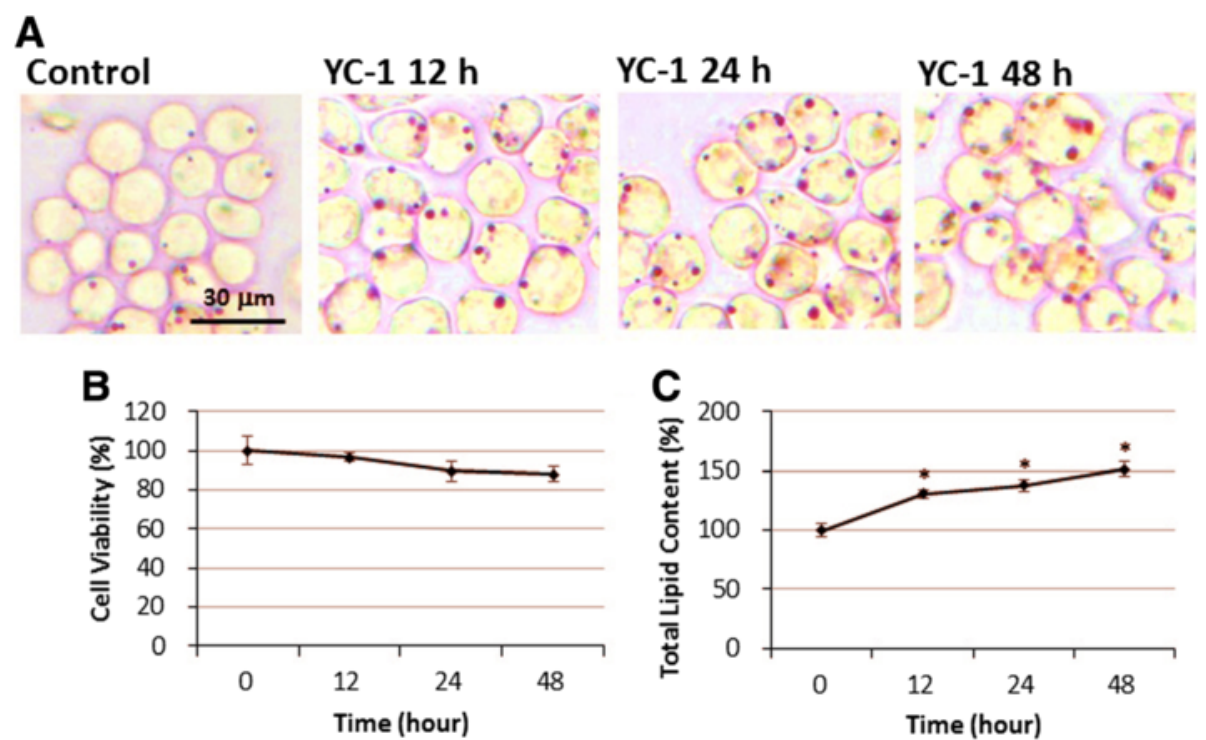

Fig. 2 Time course effect of YC-1 on lipid droplet formation and cell viability in RAW 264.7 macrophages. a Time course analysis of YC-1-induced lipid droplet formation in macrophages. RAW 264.7 macrophages were treated with $20 \mu \mathrm{M}$ YC-1 for the indicated lengths of time. After fixation and staining with oil red $\mathrm{O}$, the cells were observed by light microscopy. Scale bar $=30 \mu \mathrm{m}$. $\mathbf{b}$ Time course analysis of the cell viability of YC-1treated macrophages. RAW 264.7 macrophages were treated with $20 \mu \mathrm{M} \mathrm{YC-1} \mathrm{for} \mathrm{different} \mathrm{lengths} \mathrm{of} \mathrm{time} \mathrm{and} \mathrm{the} \mathrm{cell} \mathrm{viability} \mathrm{was} \mathrm{measured} \mathrm{by}$ MTT assay $(n=6)$. c Quantification of total lipid content of macrophages $(n=6)$. * indicates $P<0.05$ compared to the control group

macrophages. The results of oil red $\mathrm{O}$ staining show that treatment with $50 \mu \mathrm{g} / \mathrm{mL}$ ox-LDL for $24 \mathrm{~h}$ induced lipid droplet formation (Fig. 3a) but significantly decreased cell viability in macrophages (Fig. 3b). We also observed that YC-1 enhanced ox-LDL-induced lipid droplet formation.
The quantification result revealed that co-treatment with ox-LDL and $20 \mu \mathrm{M}$ YC-1 for $24 \mathrm{~h}$ significantly increased total lipid content compared to treatment with ox-LDL alone (Fig. 3c). This result indicates that YC-1 may enhance ox-LDL-induced foam cell formation in macrophages.

\section{A}
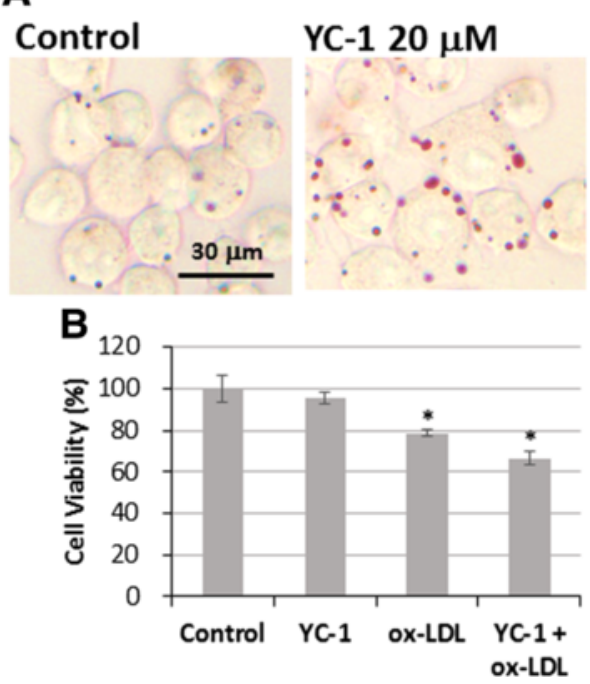

C

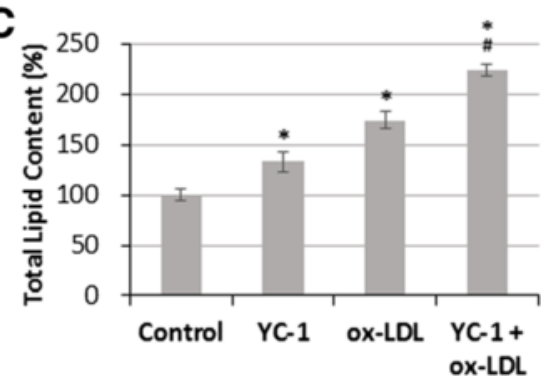

Fig. 3 Treatment with YC-1 enhances ox-LDL-mediated foam cell formation. a YC-1 increased intracellular lipid droplets in ox-LDL-treated macrophages. RAW 264.7 macrophages were treated with $20 \mu \mathrm{M} \mathrm{YC-1}$ with/without $50 \mu \mathrm{g} / \mathrm{mL}$ ox-LDL for $24 \mathrm{~h}$. After fixation and staining with oil red $\mathrm{O}$, the cells were observed by light microscopy. Scale bar $=30 \mu \mathrm{m}$. b Treatment with ox-LDL decreased the cell viability of macrophages. RAW 264.7 macrophages were treated with $20 \mu \mathrm{M} \mathrm{YC-1}$ with/without $50 \mu \mathrm{g} / \mathrm{mL}$ ox-LDL for $24 \mathrm{~h}$ and the cell viability was measured by MTT assay $(n=6)$. $\mathbf{c}$ Quantification of total lipid content of macrophages $(n=6)$. ${ }^{*}$ indicates $P<0.05$ compared to the control group; \# indicates $P<0.05$ compared to the ox-LDL-treated group 
To further confirm the effect of YC-1 on lipid droplet and foam cell formation, we used the AdipoRed ${ }^{\mathrm{im}}$ assay to label lipid accumulation in macrophages. HCS was used to quantify the total area of lipid droplets and mean fluorescence intensity in individual cells to estimate the level of intracellular lipid accumulation. The results of the HCS image analysis show that $\mathrm{YC}-1$ increased the amount of intracellular lipid compared to the control group, and enhanced ox-LDL-induced lipid accumulation in macrophages compared to the ox-LDL-treated group (Fig. 4a). Compared with the control cells, YC-1 increased the total area of lipid droplets by $75 \%$ and the mean fluorescence intensity per cell by $30 \%$ (Fig. 4b and c). Moreover, YC-1 significantly increased the total area

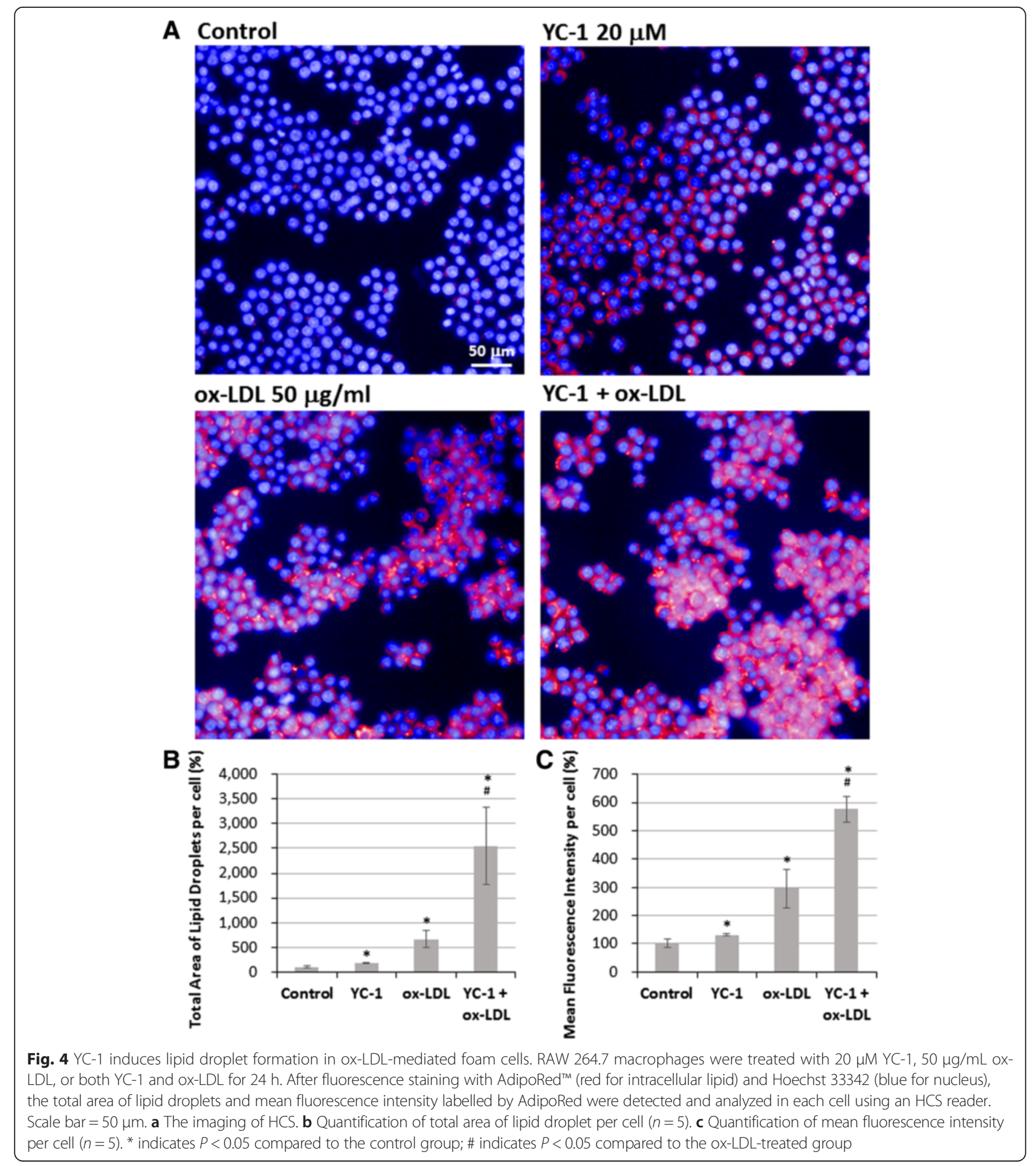




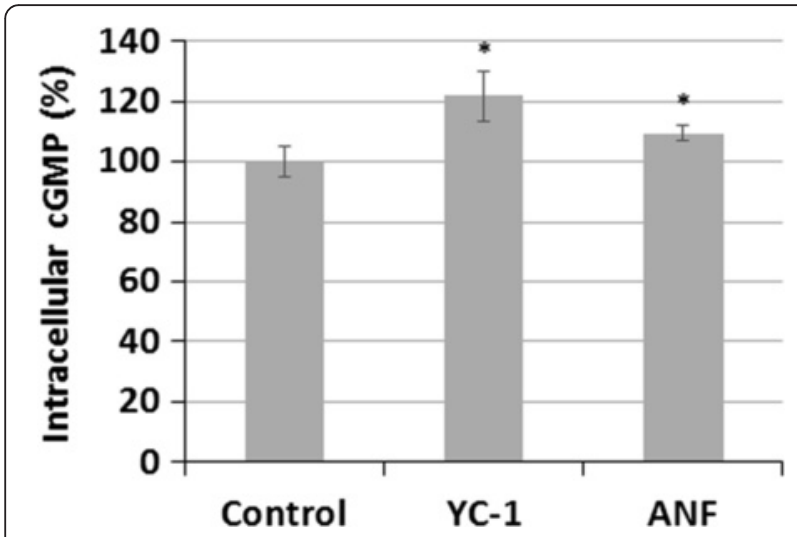

Fig. 5 YC-1 and ANF increases the level of intracellular CGMP in macrophages. RAW 264.7 macrophages were treated with $20 \mu \mathrm{M}$ YC-1 or $10 \mu \mathrm{g} / \mathrm{mL}$ ANF for $16 \mathrm{~h}$. The intracellular cGMP was measured using a cGMP Enzymeimmunoassay kit $(n=5)$. * indicates $P<0.05$ compared to the control group

of lipid droplets (by $1900 \%$ ) and the mean fluorescence intensity (by $275 \%$ ) in ox-LDL-induced lipid droplets compared to the ox-LDL-treated group (Fig. $4 \mathrm{~b}$ and c). These results further confirm that YC-1 promotes oxLDL-induced foam cell formation in macrophages.

\section{PKG inhibitor decreases YC-1-induced lipid droplet} accumulation and foam cell formation in macrophages To clarify the involvement of the sGC/cGMP/PKG signaling pathway in $\mathrm{YC}$-1-induced lipid accumulation, intracellular cGMP was measured in macrophages. The sGC activator, atrial natriuretic factor (ANF), was used as a positive control [19]. We found that treatment with $20 \mu \mathrm{M} \mathrm{YC}-1$ for $16 \mathrm{~h}$, like the treatment of the positive control ANF, significantly increased the level of cGMP (Fig. 5). The result of oil red $\mathrm{O}$ staining also revealed that the cGMP analogue dibutyryl cyclic guanosine monophosphate (db-cGMP) induced lipid droplet formation in macrophages in a manner similar to that obtained with YC-1 (Fig. 6). These findings support the idea that YC-1 may regulate lipid accumulation in macrophages through the cGMP-related pathway.

To further clarify the effect of YC-1 on lipid droplet formation in macrophages and foam cells, we used KT5823 to attenuate the activation of PKG [20]. The results of oil red O staining show that KT5823 inhibited YC-1-induced lipid droplet accumulation (Fig. 7), suggesting that $\mathrm{YC}-1$ may induce lipid accumulation in macrophages via the PKG-related signaling pathway. The HCS results revealed that KT5823 significantly inhibited YC-1-induced lipid droplet formation, as the mean fluorescence intensity per cell of KT5823-treated groups was reduced by $20 \%$ (Fig. 8a) and $140 \%$ (Fig. 8b) in macrophages and in ox-LDL-mediated macrophage foam cells, respectively. Our findings suggest that the sGC/cGMP/PKG signaling pathway may be involved in YC-1-induced lipid droplet accumulation and foam cell formation in macrophages.

\section{Discussion}

We have demonstrated that $\mathrm{YC}-1$ increases the number of intracellular lipid droplets and total lipid content in RAW 264.7 macrophages, and enhances ox-LDL-induced foam cell formation. In addition, the results show that the PKG-related signaling pathway is involved in YC-1regulated lipid droplet formation in macrophages and foam cells.

We have previously reported that $\mathrm{YC}-1$ inhibits oleateinduced lipid droplet formation, leading to lipolysis in lipid-laden macrophages [9]. Oleate, a type of unsaturated free fatty acid, is reported to inhibit cholesterol efflux in modified LDL-treated macrophages [21] and to induce triglyceride accumulation in macrophages [22]. However, ox-LDL is composed not only of triglycerides, but also of cholesterol and cholesterol esters [23-25]. The uptake of ox-LDL is through scavenger receptors and endocytosis in macrophages [26], whereas oleate is probably transported via diffusion [27]. These differences may explain the different effects of $\mathrm{YC}-1$ on the oxLDL-induced macrophage foam cells used in this study

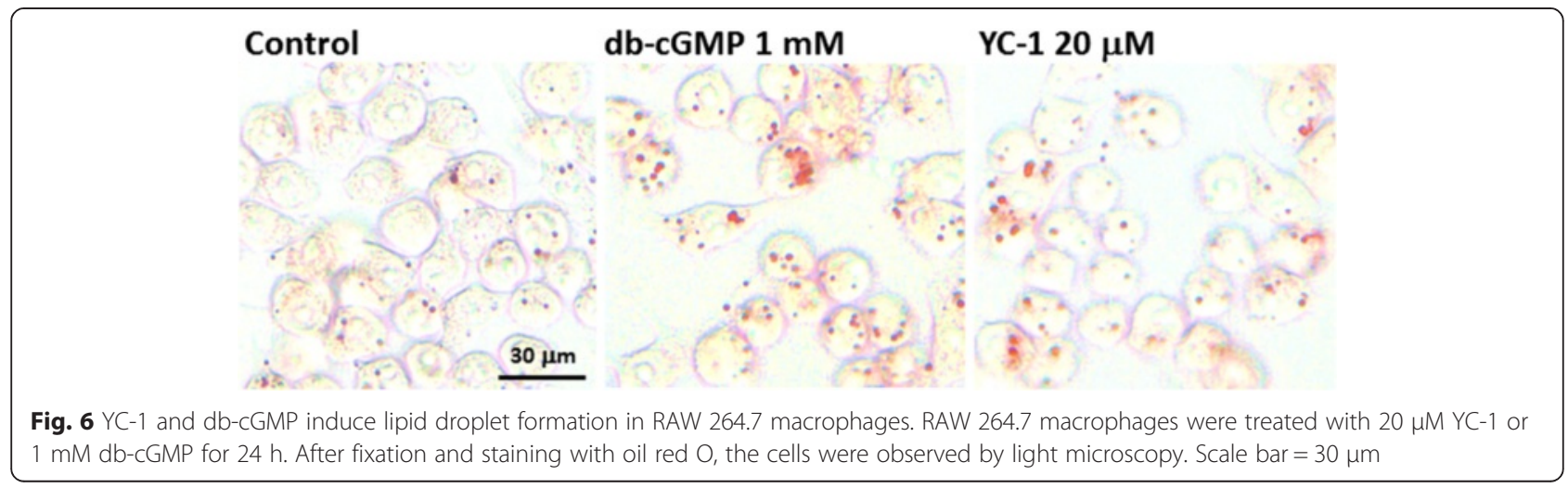




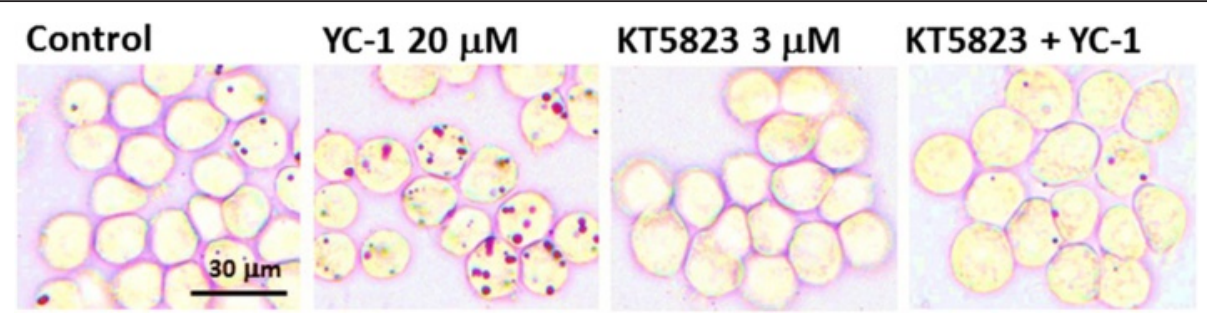

Fig. 7 The PKG inhibitor KT5823 inhibits YC-1-induced lipid droplet formation in RAW 264.7 macrophages. RAW 264.7 macrophages were treated with $20 \mu \mathrm{M}$ YC-1, $3 \mu \mathrm{M}$ KT5823 or both of YC-1 and KT5823 for $24 \mathrm{~h}$. After fixation and staining with oil red O, the cells were observed by light microscopy. Scale bar $=30 \mu \mathrm{m}$

and oleate-induced lipid-loaded macrophages. Therefore, we speculate that YC-1 may regulate scavenger receptor-mediated endocytosis, and subsequently enhance lipid droplet formation in macrophage foam cells. In addition, we have demonstrated here that $\mathrm{YC}-1$ increases the number of intracellular lipid droplets in macrophages as well as in ox-LDL-induced macrophage foam cells. This could be explained by the possibility of YC-1 increasing the clearance of fatty acids in oleate-treated macrophages, while enhancing the uptake of cholesterol or triglycerides supplied by serum or ox-LDL.

We have previously shown that treating cells with YC1 for 10 min does not affect sGC activity and cGMP levels in RAW 264.7 macrophages [9]. In contrast to this, it has also been reported that treatment of J774A.1 macrophages with $\mathrm{YC}-1$ (20 and $40 \mu \mathrm{M})$ for $24 \mathrm{~h}$ significantly increases intracellular cGMP [28]. In this study, we showed that $\mathrm{YC}-1$, as well as the sGC activator ANF, increased the level of intracellular cGMP at $16 \mathrm{~h}$. The result of oil red $\mathrm{O}$ staining revealed that YC1 and the cGMP analogue db-cGMP induced lipid droplet formation in macrophages. We also demonstrated that the PKG inhibitor KT5823 inhibits YC-1induced lipid droplet formation in RAW 264.7 macrophages and foam cells, as evidenced by the reduction of the mean fluorescence intensity (per cell) in KT5823treated cells. In addition, it seems that a longer treatment with YC-1 (e.g., 24 h) may be required to continually activate the sGC/cGMP/PKG pathway in macrophages and induce lipid droplet and foam cell formation. In addition, previous studies have demonstrated that treatment with $100 \mu \mathrm{g} / \mathrm{ml}$ ox-LDL for $4 \mathrm{~h}$ had no impact on the level of cGMP in human monocyte-derived macrophages [29]. However, nitric oxide could regulate apoptosis of macrophages through guanylate cyclase stimulation [29]. According to the study of Chen et al., ox-LDL can decrease intracellular cGMP in human platelets [30]. Similarly, ox-LDL has been reported to activate human platelets through inhibition of the cGMP signaling cascade in the study of Magwenzi et al. [31]. These studies have clearly revealed the possible relationship among oxLDL, cGMP, and sGC/cGMP/PKG cascades.
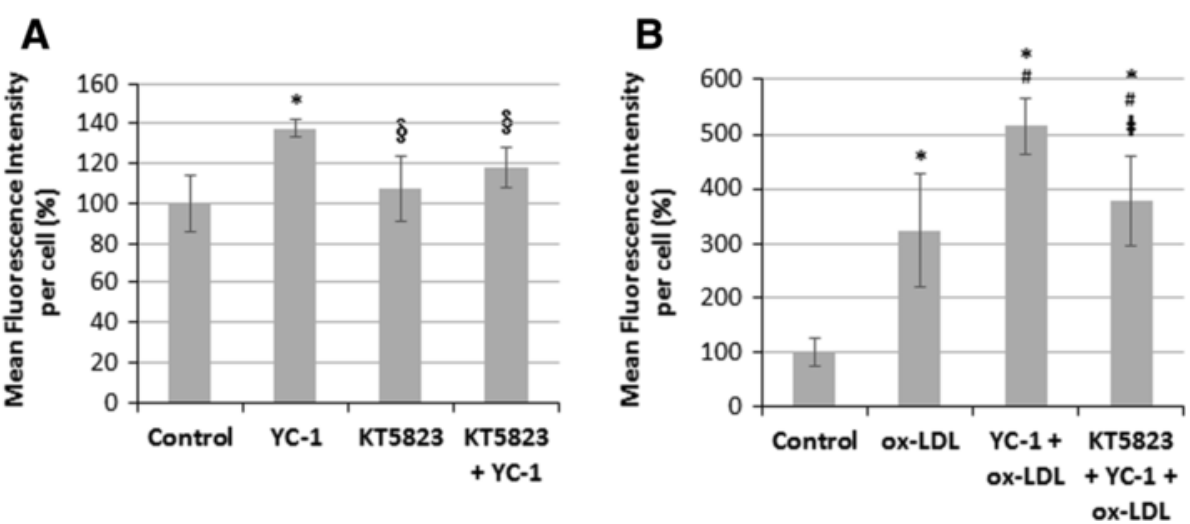

Fig. 8 PKG inhibitor reduces YC-1-stimulated lipid accumulation in macrophages and ox-LDL-mediated foam cells. a PKG inhibitor reduced YC-1induced lipid accumulation in macrophages. RAW 264.7 macrophages were treated with or without $3 \mu \mathrm{M}$ KT5823, and then exposed to $20 \mu \mathrm{M}$ YC-1 for $24 \mathrm{~h}$. After fluorescence staining with AdipoRed ${ }^{\mathrm{TM}}$ and Hoechst, the mean fluorescence intensity (AdipoRed) per cell was detected and analyzed by an HCS reader $(n=5)$. b PKG inhibitor reduced YC-1-induced lipid accumulation in ox-LDL-mediated foam cells. RAW 264.7 macrophages were treated with or without $3 \mu \mathrm{M} \mathrm{KT5823,} \mathrm{and} \mathrm{then} \mathrm{exposed} \mathrm{to} 20 \mu \mathrm{M} \mathrm{YC-1}$ and $50 \mu \mathrm{g} / \mathrm{mL}$ ox-LDL for $24 \mathrm{~h}$. After fluorescence staining with AdipoRedTM and Hoechst, the mean fluorescence intensity (AdipoRed) per cell was detected and analyzed by an HCS reader $(n=5)$. ${ }^{*}$ indicates $P<0.05$ compared to the control group; $\S$ indicates $P<0.05$ compared to the $Y C-1$-treated group; \# indicates $P<0.05$ compared to the ox-LDL-treated group; $¥$ indicates $P<0.05$ compared to the $Y C$ - 1 and ox-LDL-treated group 
HCS, consisting of automated microscopy and image analysis, is a new technology that has been applied to drug discovery and cell biology [32]. It has also been used to identify specific proteins or cellular structures with immunoreagents, organic dyes, genetically-encoded fluorescent proteins or quantum dots [33]. Using the technique of HCS with hydrophobic fluorescence dye to detect intracellular lipid droplets and ox-LDL-induced lipid accumulation in macrophages has been reported in the research literature [18]. To estimate the level of intracellular lipid accumulation, we used HCS and AdipoRed $^{\mathrm{m}}$ assay to label and quantify the total area of lipid droplets and the mean fluorescence intensity per cell. Tsou et al. have shown that YC-1 can decrease cholesterol content in ox-LDL-treated macrophages through activation of sGC, but that the protein level of scavenger receptor class A did not change [28]. In contrast, we used HCS and the AdipoRed ${ }^{\text {Tax }}$ assay to quantify lipid droplet and foam cell formation in macrophages instead of the cholesterol content assay, as foam cells are defined as being "full of intracellular lipid droplets" in macrophages and smooth muscle cells.

YC-1 is a promising antiangiogenic anticancer agent that functions by targeting HIF- $1 \alpha$ and has effectively prevented tumor growth in immunodeficient mice grafted with five types of human tumor cells and in Hep3B cells $[34,35]$. Yeo et al. have proposed that YC-1 should be regarded as a good lead compound for the development of novel antiangiogenic and anticancer agents [36]. Our current data suggest that YC-1 enhances oxLDL-mediated lipid accumulation and foam cell formation, which may in turn contribute to atherosclerosis. Hence, this chemical should be used cautiously in future clinical trials.

\section{Conclusion}

In summary, $\mathrm{YC}-1$ induces lipid droplet formation in macrophages, possibly via an sGC/cGMP/PKG-related pathway.

\section{Abbreviations \\ ANF: Atrial natriuretic factor; cGMP: cyclic guanosine monophosphate; db- CGMP: dibutyryl cyclic guanosine monophosphate; HCS: high content screening; MTT: 3-(4,5-cimethylthiazol-2-yl)-2,5-diphenyl tetrazolium bromide; ox-LDL: oxidized low density lipoprotein; PKG: CGMP-dependent protein kinase; SGC: soluble guanylate cyclase; YC-1: 3-(5'-Hydroxymethyl-2'-furyl)-1- benzyl indazole.}

\section{Competing interests}

The authors declare that they have no competing interests.

\section{Authors' contributions}

LT conceived of the study, carried out the experiments, performed the statistical analysis and drafted the manuscript. HPH helped to draft the manuscript. SFC contributed to experiments and helped draft the manuscript. THF and IJW helped draft the manuscript and the final revisions. All authors read and approved the final draft.

\section{Acknowledgments}

This work was supported by Taiwan National Science Council grants NSC102-2314-B-002-112-MY3. We especially appreciate the assistance of the National RNAi Core Facility (Academia Sinica, Taipei, R.O.C.) with the HCS experiment.

\section{Author details}

'Department of Ophthalmology, National Taiwan University Hospital, Taipei 100, Taiwan. ${ }^{2}$ Graduate Institute of Medical Sciences, College of Medicine, Taipei Medical University, Taipei, Taiwan. ${ }^{3}$ Graduate Institute of Medical Genomics and Proteomics, College of Medicine, National Taiwan University, Taipei, Taiwan. ${ }^{4}$ Department of Anatomy, School of Medicine, College of Medicine, Taipei Medical University, Taipei 110, Taiwan.

Received: 13 November 2015 Accepted: 11 January 2016 Published online: 15 January 2016

\section{References}

1. Gordon S, Taylor PR. Monocyte and macrophage heterogeneity. Nat Rev Immunol. 2005:5(12):953-64. doi:10.1038/nri1733.

2. Stefater 3rd JA, Ren S, Lang RA, Duffield JS. Metchnikoff's policemen: macrophages in development, homeostasis and regeneration. Trends Mol Med. 2011;17(12):743-52. doi:10.1016/j.molmed.2011.07.009.

3. Wynn TA, Chawla A, Pollard JW. Macrophage biology in development, homeostasis and disease. Nature. 2013;496(7446):445-55. doi:10.1038/nature12034.

4. Shashkin P, Dragulev B, Ley K. Macrophage differentiation to foam cells. Curr Pharm Des. 2005;11(23):3061-72.

5. Li AC, Glass CK. The macrophage foam cell as a target for therapeutic intervention. Nat Med. 2002;8(11):1235-42. doi:10.1038/nm1102-1235.

6. Kunjathoor W, Febbraio M, Podrez EA, Moore KJ, Andersson L, Koehn S, et al. Scavenger receptors class $\mathrm{A}-1 / \mathrm{Il}$ and $\mathrm{CD} 36$ are the principal receptors responsible for the uptake of modified low density lipoprotein leading to lipid loading in macrophages. J Biol Chem. 2002;277(51):49982-8. doi:10.1074/jbc.M209649200.

7. Moore K, Tabas I. Macrophages in the pathogenesis of atherosclerosis. Cell. 2011;145(3):341-55. doi:10.1016/j.cell.2011.04.005.

8. Glass CK, Witztum JL. Atherosclerosis. the road ahead. Cell. 2001;104(4):503-16.

9. Chin $\mathrm{CH}$, Hwang $T L$, Chang $C C$, Liu CL, Lee JJ, Tsui L, et al. YC-1 inhibits lipid droplet accumulation and induces lipolysis in lipid-laden RAW264.7 macrophages. J Food Drug Anal. 2011;19(4):437-44.

10. Ko FN, Wu CC, Kuo SC, Lee FY, Teng CM. YC-1, a novel activator of platelet guanylate cyclase. Blood. 1994;84(12):4226-33.

11. Francis SH, Busch JL, Corbin JD, Sibley D. cGMP-dependent protein kinases and CGMP phosphodiesterases in nitric oxide and cGMP action. Pharmacol Rev. 2010;62(3):525-63. doi:10.1124/pr.110.002907.

12. Hwang $T L$, Wu CC, Guh $J H$, Teng CM. Potentiation of tumor necrosis factoralpha expression by YC-1 in alveolar macrophages through a cyclic GMPindependent pathway. Biochem Pharmacol. 2003;66(1):149-56.

13. Hwang TL, Tang MC, Kuo LM, Chang WD, Chung PJ, Chang YW, et al. YC-1 potentiates CAMP-induced CREB activation and nitric oxide production in alveolar macrophages. Toxicol Appl Pharmacol. 2012;260(2):193-200. doi:10.1016/j.taap.2012.02.011.

14. Hsiao G, Huang HY, Fong TH, Shen MY, Lin $C H$, Teng $C M$, et al. Inhibitory mechanisms of YC-1 and PMC in the induction of INOS expression by lipoteichoic acid in RAW 264.7 macrophages. Biochem Pharmacol. 2004; 67(7):1411-9. doi:10.1016/j.bcp.2003.12.010.

15. Chou YY, Gao Jl, Chang SF, Chang PY, Lu SC. Rapamycin inhibits lipopolysaccharide induction of granulocyte-colony stimulating factor and inducible nitric oxide synthase expression in macrophages by reducing the levels of octamer-binding factor-2. FEBS J. 2011;278(1):85-96. doi:10.1111/j.1742-4658.2010.07929.x

16. Chou DS, Hsiao G, Shen MY, Fong TH, Lin CH, Chen TF, et al. Low concentration of oxidized low density lipoprotein suppresses platelet reactivity in vitro: an intracellular study. Lipids. 2004;39(5):433-40.

17. Ramirez-Zacarias JL, Castro-Munozledo F, Kuri-Harcuch W. Quantitation of adipose conversion and triglycerides by staining intracytoplasmic lipids with Oil red O. Histochemistry. 1992;97(6):493-7.

18. Grandl M, Schmitz G. Fluorescent high-content imaging allows the discrimination and quantitation of E-LDL-induced lipid droplets and Ox- 
LDL-generated phospholipidosis in human macrophages. Cytometry A. 2010;77(3):231-42. doi:10.1002/cyto.a.20828.

19. Mattana J, Singhal PC. Effects of atrial natriuretic peptide and CGMP on uptake of IgG complexes by macrophages. Am J Physiol. 1993;265(1 Pt 1): C92-8.

20. Hwang TL, Wu CC, Guh JH, Teng CM. Potentiation of tumor necrosis factor-alpha expression by YG-1 in alveolar macrophages through a cyclic GMP-independent pathway. Biochem Pharmacol. 2003;66(1):149-56. doi:10.1016/S0006-2952(03)00202-8.

21. Wang Y, Oram JF. Unsaturated fatty acids inhibit cholesterol efflux from macrophages by increasing degradation of ATP-binding cassette transporter A1. J Biol Chem. 2002;277(7):5692-7. doi:10.1074/jbc.M109977200.

22. Newsholme P, Newsholme EA. Rates of utilization of glucose, glutamine and oleate and formation of end-products by mouse peritoneal macrophages in culture. Biochem J. 1989:261(1):211-8.

23. Levitan I, Volkov S, Subbaiah PV. Oxidized LDL: diversity, patterns of recognition, and pathophysiology. Antioxid Redox Signal. 2010;13(1):39-75. doi:10.1089/ars.2009.2733.

24. Basu SK, Brown MS, Ho YK, Goldstein JL. Degradation of low density lipoprotein. dextran sulfate complexes associated with deposition of cholesteryl esters in mouse macrophages. J Biol Chem. 1979;254(15):7141-6.

25. Steinberg D. Low density lipoprotein oxidation and its pathobiological significance. J Biol Chem. 1997;272(34):20963-6.

26. Boullier A, Bird DA, Chang MK, Dennis EA, Friedman P, Gillotre-Taylor K, et al. Scavenger receptors, oxidized LDL, and atherosclerosis. Ann N Y Acad Sci. 2001;947:214-22. discussion 22-3.

27. Stewart JM, Driedzic WR, Berkelaar JA. Fatty-acid-binding protein facilitates the diffusion of oleate in a model cytosol system. Biochem J. 1991;275(Pt 3): 569-73.

28. Tsou CY, Chen CY, Zhao JF, Su KH, Lee HT, Lin SJ, et al. Activation of soluble guanylyl cyclase prevents foam cell formation and atherosclerosis. Acta Physiol. 2014;210(4):799-810. doi:10.1111/apha.12210.

29. Heinloth A, Brune B, Fischer B, Galle J. Nitric oxide prevents oxidised LDLinduced p53 accumulation, cytochrome $\mathrm{c}$ translocation, and apoptosis in macrophages via guanylate cyclase stimulation. Atherosclerosis. 2002;162(1): 93-101.

30. Chen LY, Mehta P, Mehta JL. Oxidized LDL decreases L-arginine uptake and nitric oxide synthase protein expression in human platelets: relevance of the effect of oxidized LDL on platelet function. Circulation. 1996;93(9):1740-6.

31. Magwenzi S, Woodward C, Wraith KS, Aburima A, Raslan Z, Jones H, et al. Oxidized LDL activates blood platelets through CD36/NOX2-mediated inhibition of the cGMP/protein kinase G signaling cascade. Blood. 2015; 125(17):2693-703. doi:10.1182/blood-2014-05-574491.

32. Zock JM. Applications of high content screening in life science research. Comb Chem High Throughput Screen. 2009;12(9):870-6.

33. Zanella F, Lorens JB, Link W. High content screening: seeing is believing Trends Biotechnol. 2010;28(5):237-45. doi:10.1016/j.tibtech.2010.02.005.

34. Chun YS, Yeo EJ, Choi E, Teng CM, Bae JM, Kim MS, et al. Inhibitory effect of YC-1 on the hypoxic induction of erythropoietin and vascular endothelial growth factor in Hep3B cells. Biochem Pharmacol. 2001;61(8):947-54.

35. Yeo EJ, Chun YS, Cho YS, Kim J, Lee JC, Kim MS, et al. YC-1: a potential anticancer drug targeting hypoxia-inducible factor 1. J Natl Cancer Inst. 2003;95(7):516-25.

36. Yeo EJ, Chun YS, Park JW. New anticancer strategies targeting HIF-1. Biochem Pharmacol. 2004;68(6):1061-9. doi:10.1016/j.bcp.2004.02.040.

\section{Submit your next manuscript to BioMed Central and we will help you at every step:}

- We accept pre-submission inquiries

- Our selector tool helps you to find the most relevant journal

- We provide round the clock customer support

- Convenient online submission

- Thorough peer review

- Inclusion in PubMed and all major indexing services

- Maximum visibility for your research

Submit your manuscript at www.biomedcentral.com/submit
() BioMed Central 